\title{
Henoch-Scholein Purpura (HSP): A Clinico-etiological Study
}

\author{
Kareem $N S^{1}$, Riyaz $N^{2}$ \\ ${ }^{I}$ Assistant Professor, Department of Dermatology, \\ Venereology and Leprology, Sree Narayana Institute \\ of Medical Sciences, Chalakka 683 594, Kochi, \\ Kerala, India \\ ${ }^{2}$ Professor \& HOD, Department of Dermatology, \\ Venereology and Leprology, Government Medical \\ College, Calicut 673 008, Kerala, India
}

\section{Address for correspondence}

Dr. Semeena N. K.

Department of Dermatology, Venereology and Leprology

Sree Narayana Institute of Medical Sciences

Chalakka - 683 594, Ernakulam (Dt)

Kerala, India

Mobile: +91 8289866399

Email: sameenahabeeb@ymail.com

\section{Citation}

Kareem NS, Riyaz N. Henoch-schonlein purpura (HSP): a clinic-etiological study. NJDVL 2014; 12(1): $28-33$.

\begin{abstract}
Background: Henoch-Schönlein (HSP) is a small vessel vasculitis affecting skin and internal organs.
\end{abstract}

Objectives: To determine the age group affected, etiological factors, clinical features, complications and association with other diseases.

Methods: The study included 50 patients over a period of 3 years selected on the modified criteria by American College of Rheumatology. Clinical assessment was done and investigated for any focus of hidden infections especially Dental and ENT by respective departments. Associated conditions, complications and recurrence were also observed.

Results: All patients had palpable purpura (pruritic in 58\% and with hemorrhagic bullae in 6\%) with upper respiratory tract prodrome (44\%), joint involvement (94\%) and gastrointestinal symptoms (90\%). Precipitating factors were sore throat $(74 \%)$, caries tooth $(44 \%)$, drugs (30\%) and food (16\%) in varying combinations. On investigation $56 \%$ had raised ESR and $22 \%$ were with abnormal peripheral smears. All biopsies showed leucocytoclastic vasculitis. Occult blood in stool was detected in $10 \%$ and $2 \%$ showed Streptococci in throat swab culture. Renal involvement was 54\% (RBC and albumin-42\%, RBC alone-12\%). One patient had intestinal perforation. Bleeding time, clotting time, platelet count, cryoglobulin, ANA, rheumatoid factor, HBs Ag, VDRL and X-ray chest were within normal limits. LE cell test was negative. Follow up study showed recurrence in $98 \%$.

Conclusion: HSP is a small vessel vasculitis in response to any unknown foreign or endogenous antigen. The age of onset varied from below 7 to 58 years, with most of them below 20. The most important clinical presentation was palpable purpura in lower extremities. GIT and joint involvement were more. Renal involvement found to be the most common complication.

Key Words: Abdominal Pain, Arthritis, Melena, Palpable Purpura, Renal Complications

\section{Introduction}

Henoch-Schönlein Purpura (HSP) is an IgA mediated systemic small vessel vasculitis commonly affecting joints, gastrointestinal tract (GIT) and kidneys. ${ }^{1}$ This was first reported by
Heberden in $1801 .^{2}$ In 1837 Schönlein described association of purpura and joint pain and termed this as "peliosis rheumatica". In 1874 and 1899 , Henoch added GIT and renal manifestations to that description respectively. ${ }^{3}$ 


\section{Original Article}

The disease can occur in all age groups. ${ }^{2}$ Most commonly incriminated organism is Streptococcus ${ }^{4}$, other responsible factors are bacteria, ${ }^{5}$ virus, ${ }^{6}$ food $^{7}$ and drugs. ${ }^{8}$ Exact etiology is not known. The HLA associations mentioned are HLA DQA1, DRB1, HLAB35 and HLA B18. ${ }^{9}$ It has association with diseases like lymphoma, leukemia, solid tumors ${ }^{10}$ and guttate psoriasis. ${ }^{11}$

\section{Material and Methods}

This study was conducted in department of Dermatology, Government Medical College, Calicut, India over a period of 3 years. The study population included 50 patients fitting into clinical presentation of HSP. All of them consented for study, and it was approved by Institutional Ethical Committee. Diagnosis of HSP was based on modified American College of Rheumatology Criteria (ARC criteria 1990) put forward by Helander, De Castro and Gibson (more than 90\% sensitivity and specificity). ${ }^{12}$ Palpable purpura, age of onset, GIT symptoms and histopathological evidence of vasculitis were taken into account. Immunofluorescence was done only in patients above age 30 (13 patients) due to socioeconomical reasons, to satisfy the criteria. (Diagnostic Criteria - Table 1)

Table 1: Criteria for diagnosis of HSP in patients with skin lesions of vasculitis or histologic evidence of leukocytoclastic vasculits, or both (any three out of the following should be present)

\begin{tabular}{l|l}
\hline 1 & $\begin{array}{l}\text { Direct immunofluorescence study } \\
\text { suggesting vasculitis with IgA vascular } \\
\text { deposits }\end{array}$ \\
\hline 2 & Age $<30$ years at the onset of symptoms \\
\hline 3 & Gastro intestinal involvement \\
\hline 4 & Upper respiratory tract infection prodrome \\
\hline 5 & $\begin{array}{l}\text { Mesangioproliferative glomerulonephritis } \\
\text { on renal biopsy with or without IgA } \\
\text { deposition }\end{array}$ \\
\hline
\end{tabular}

(The American College of Rheumatology 1990 criteria - modified by Helander,De Castro and Gibson-with aspecificity and sensitivity $>90 \%$ ) Particular emphasis was given to age of patients, sex, onset of lesions, site, spread and associated pruritus. Abdominal symptoms, arthralgia and renal symptoms were recorded. Precipitating factors like food, drugs and infections were noted. Familial occurrence was documented. A thorough physical examination for associated diseases was made and findings recorded. Dental and ENT check up for hidden infections were carried out by respective departments. Patients were advised to maintain a food diary to observe if any food item was the responsible cause.

Laboratory investigations included routine blood and urine, bleeding time, clotting time, platelet count, LE cell, random blood sugar, ASO titre, serum electrolytes, cryoglobulins, ANA, RA factor, HBs Ag, VDRL, benzidine test for stool occult blood, renal function test, liver function test, peripheral smear, throat swab culture and sensitivity, X-ray chest and skin biopsy.

\section{Results}

Age of the affected patients varied from 7 to 58 years (Mean 23.1 \pm 14.6 years, Median: 18.5). Fifty four percentage of the patients were below 20 years. As age advanced, occurrence of the lesion also decreased. The study revealed male to female ratio as $1: 1.9$.

Palpable purpuric lesions were the main clinical presentation of the disease $(100 \%)$. Palpable purpura with hemorrhagic bullae were present in $6 \%$ (Figure 1).

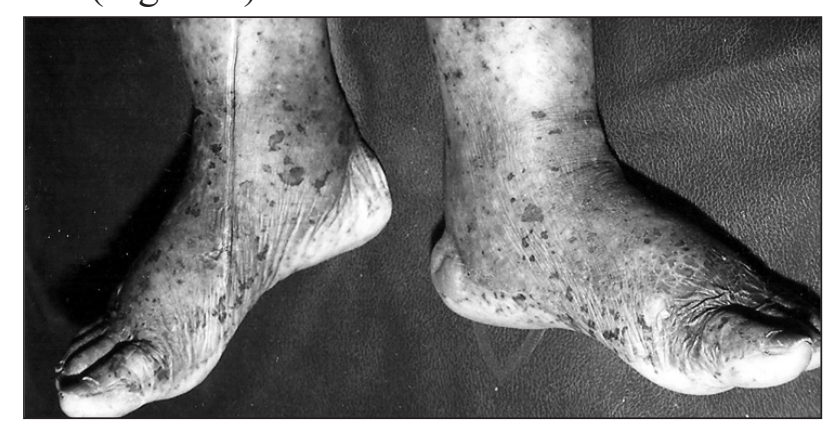

Figure 1: HSP with haemorrhagic bullae 


\section{Original Article}

The lesions were pruritic in 58\% and pain along with pruritus noted in $2 \%$. Lesions were mostly concentrated on extensor aspect of the extremities. Fifty two percentage were on the extensor aspect of the lower limb (Figure 2 ) and 12\% on extensor aspect of the upper limb (Figure 3) and lower limb. Truncal involvement was minimal (2\%).

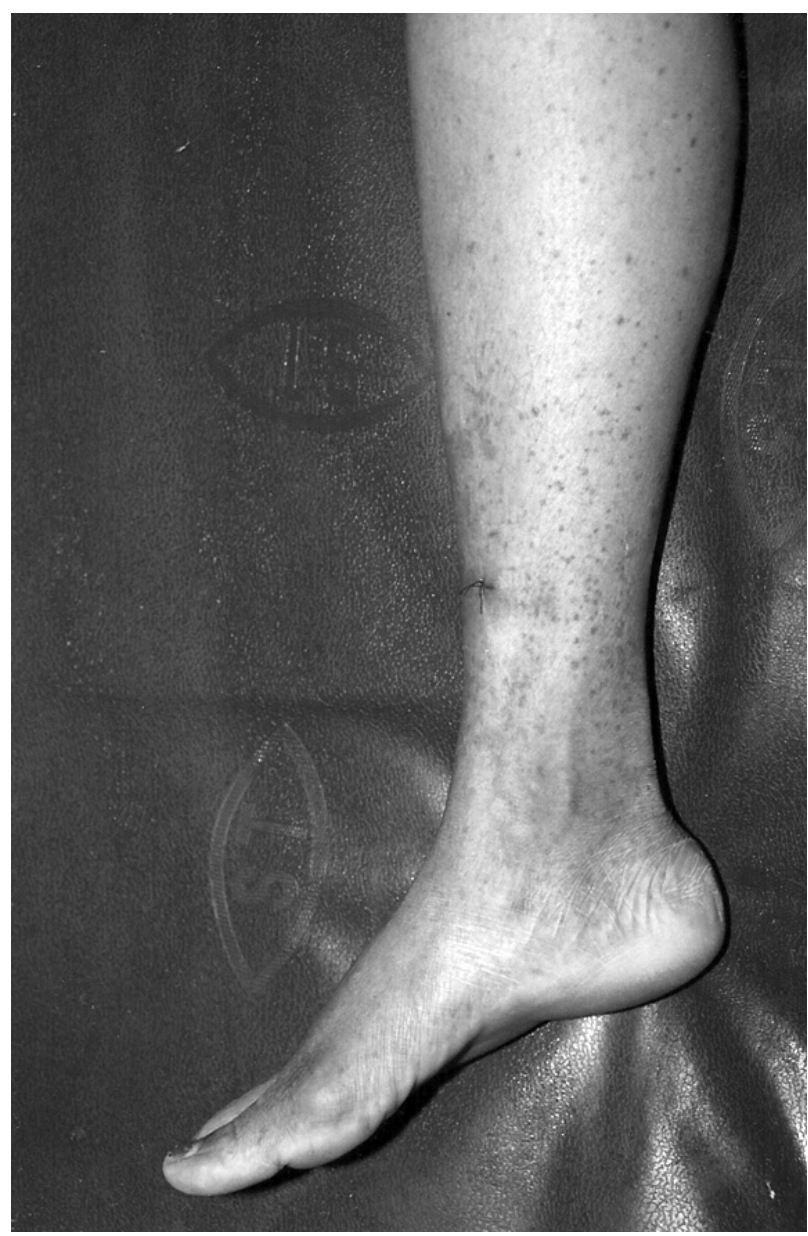

Figure2: Palpable purpura on lower limb

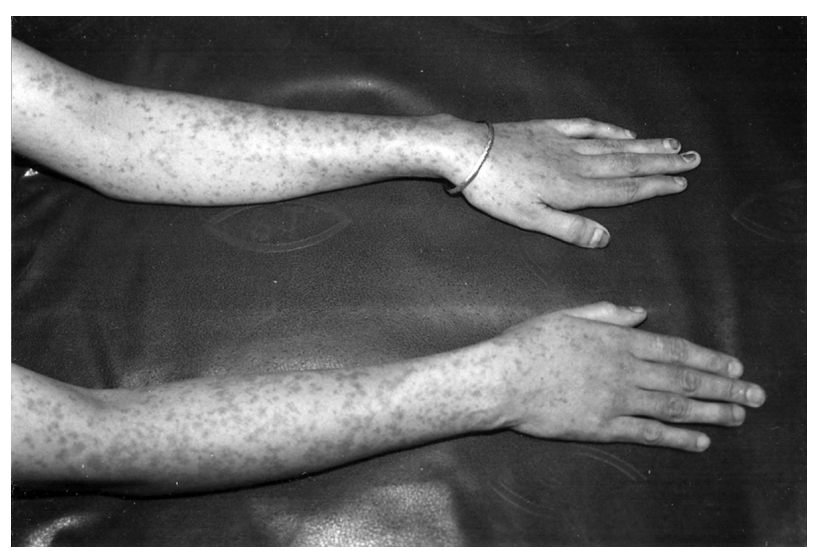

Figure 3: Palpable purpura on upper limbs
Seventy Four percentage of the patients had upper respiratory tract infections. Pain during micturation was also noted in $8 \%$.

Patients with gastrointestinal tract involvement showing abdominal pain were $44 \%$. Rest of the patients had abdominal pain, melena, haematemesis and vomiting in combinations (Table 2). Ninety four percentage of the patients had joint involvement. The arthritis varied from mono (4\%), oligo (22\%) to polyarthritis $(68 \%)$. Ankle was the most commonly affected joint (64\%). Nature of the joint involvement varied from non-fleeting (56\%) to fleeting (38\%).

Table 2: Details of gastrointestinal symptoms reported by patients

\begin{tabular}{l|l|c}
\hline S.N. & Symptoms & \% of patients \\
\hline 1 & Abdominal pain & 44 \\
2 & Abdominal pain, melena, & \\
& vomiting & 6 \\
3 & Abdominal pain, hematemesis & 6 \\
4 & Abdominal pain, melena, & \\
& vomiting, diarrhoea & 10 \\
5 & Abdominal pain, diarrhoea & 6 \\
6 & Abdominal pain, melena & 6 \\
7 & Abdominal pain, vomiting & 8 \\
8 & Abdominal pain, vomiting, & \\
& diarrhoea & 4 \\
9 & Vomiting & 2 \\
10 & No symptoms & 10 \\
\hline & Total & 100 \\
\hline
\end{tabular}

Precipitating factors detected were sore throat $(66 \%)$, caries tooth $(40 \%)$, food (16\%) and Drugs $(30 \%)$ in multiple combinations. (Patients were rechallenged with food but not with drugs due to ethical reasons). Leg ulcer, pyoderma, diabetes mellitus, hypertension, tuberculosis, psoriasis and infected wounds were other factors found in association with this disorder. 


\section{Original Article}

Forty four percent of the patients had normal laboratory investigation report. Rest on blood routine examination showed raised ESR in 40\%, raised ESR with neutrophilia in $10 \%$, raised ESR with neutrophilia and eosinophilia $4 \%$ and raised ESR with lymphocytosis $2 \%$.

Bleeding time and clotting time were within normal range in all patients. Twenty two percentages showed higher values for random blood sugar and $6 \%$ revealed raised ASO titre. On urine examination, $42 \%$ showed albuminuria with hematuria and $12 \%$ showed only hematuria.

Out of 50 peripheral smears $22 \%$ showed abnormalities which included presence of toxic granules (8\%), neutrophilia (12\%) and nutrophilia with eosinophilia (2\%). Renal function test and liver function test were normal in all patients. None of them showed LE cell positivity. Skin biopsy was done in all 50 patients and results showed leukocytoclastic vasculitis (Figure $4 \&$ Figure 5). Immunofluorescence done in $26 \%$ showed IgA vascular deposits.

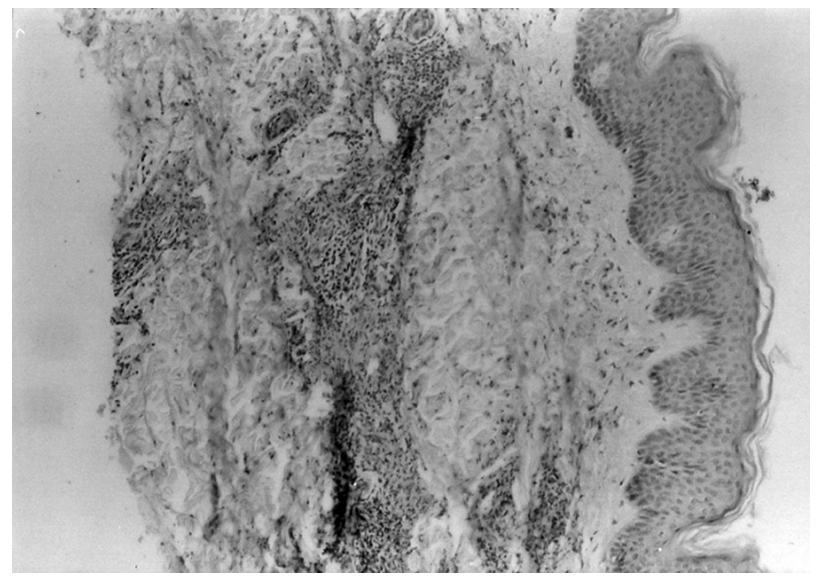

Figure 4: Leukocytoclastic vasculitis (H\&E x10)

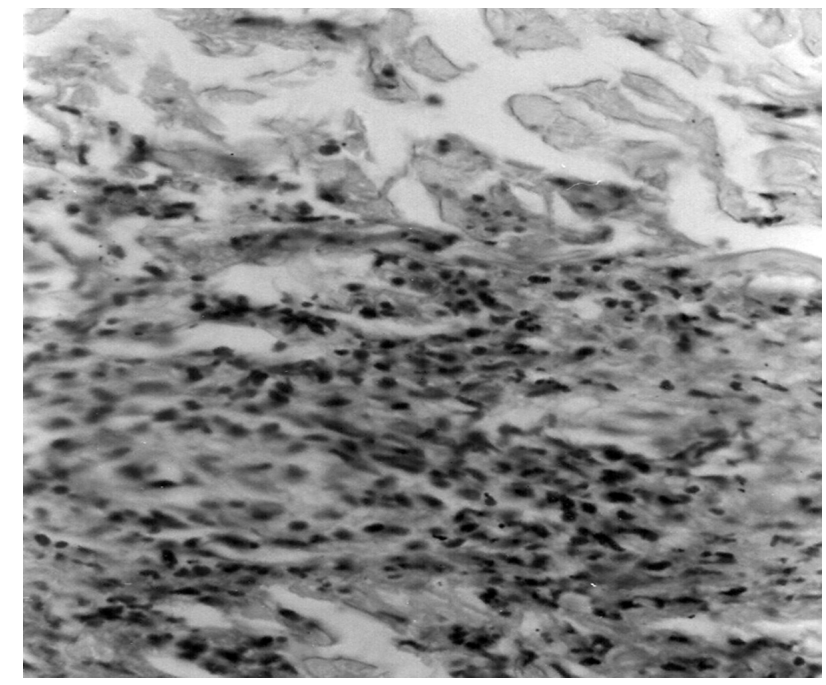

Figure 5: Leukocytoclastic vasculitis (H\&E x40)

Two percentages of the patients showed streptococci on throat swab culture and sensitivity and others revealed normal flora. Stool benzidine test for occult blood was positive in $10 \%$. All chest X-rays were within normal limits. To exclude other causes of systemic vasculitis; cryglobulins, ANA, rheumatoid factor, $\mathrm{Hbs} \mathrm{Ag}$ and VDRL were done and these found to be negative in all patients.

Ninety eight percentage of the patients showed recurrence out of which $82 \%$ had 1 to 5 times and $16 \%$ had 6 to 10 times. The most susceptible age group was between 20 and 40 years. Renal involvement was the most common complication found among this age group (28\%).

\section{Discussion}

HSP is a small vessel vasculitis affecting skin and other internal organs ${ }^{1}$. It can occur at any $\operatorname{age}^{2}(2)$. In this study $54 \%$ of patients were under 20 years, out of this $14 \%$ were under 10 years and $40 \%$ were between 10 and 20years.

The present study revealed a female predominance (male/female ratio - 1:1.9) where as others reported male predominance ${ }^{1}$. There was increased incidence in June to December like other studies which showed increased incidence in winter and spring. ${ }^{13}$ 


\section{Original Article}

According to epidemiological studies, the etiological factor may be an infectious agent and $50-75 \%$ of patients had history of preceding upper respiratory tract infection, ${ }^{14}$ but we also found that in $74 \%$. Other diseases associated with this entity observed were leg ulcer $(6 \%)$, pyoderma $(8 \%)$, diabetes mellitus $(6 \%)$, hypertension $(6 \%)$, tuberculosis (4\%), otitis (2\%) and psoriasis $(2 \%)$. A case of guttate psoriasis associated with HSP has been reported in literature. ${ }^{11}$

Drugs like ampicillin, penicillin, quinine, chloropromazine, ranitidine, cefuroxime, diclofenac, enalapril and captopril and food containing salicylates and azodyes have been implicated as etiological factors. ${ }^{13}$ Present study revealed drugs like antibiotics (ampicillin-4\%), anti-inflammatory drugs (ibuprufen-4\%, diclophenac- $2 \%$ ), antidiabetics- $4 \%$, antacid- $2 \%$ and ayurvedic drugs- $14 \%$ as responsible factors mainly in adults. Food items such as beef (4\%), green gram (4\%), fish $(6 \%)$ and banana $(2 \%)$ were also revealed as etiological factors.

We did not observe familial incidence in this study which was documented by others in rare instances. ${ }^{15}$ People in the same family had disease at the same time, but they were not blood relatives (sister-in-laws), indicating possible viral etiology.

Bilateral palpable purpura was present in all patients in which $58 \%$ were pruritic, only $6 \%$ showed hemorrhagic bullae, which was reported in literature. ${ }^{16}$ Lesions mainly seen in lower limb $(52 \%)$ which explains the effect of gravity. Trunkal involvement was only in $2 \%$, that too in bed ridden patients which also explained the effect of gravity. The purpuric lesions flattened and became nonpalpable in one or two days.

Ninety four percent of patients, included in this study exhibited joint involvement. Literature revealed joint involvement only in $60-84 \%$ of cases. ${ }^{3}$ Sixty eight percentage of our patients had polyarticular type of arthritis mainly involving knee and ankle joints. The joint involvement left no deformity.

Gastrointestinal symptoms were noted in $90 \%$ of cases. It was found to be $35-80 \%$ in literature. ${ }^{17}$ Abdominal pain was the most predominant (44\%) symptom. Others included melena, vomiting, diarrhoea and haematemesis (Table 2). Fourteen percentage had melena and $6 \%$ haemetemesis compared to $15 \%$ and $50 \%$ respectively in other studies. $^{13,17}$

Positive ASO titre indicates upper respiratory tract infection with streptococcal species which was reported as a predisposing factor in as $50 \%$ of patients, ${ }^{18}$ but in our study throat swab culture and sensitivity revealed streptococci infection in $2 \%$ of cases only.

Histopathological results of all patients showed leucocytoclastic vasculitis which was also observed by others. ${ }^{19}$ Raised ESR (56\%) and presence of toxic granules $(8 \%)$, neutrophilia $(12 \%)$ in peripheral smear points to an infective etiology.

Occult gastrointestinal bleeding was reported in HSP. ${ }^{20}$ Ten percentage of our patients showed gastrointestinal bleeding.

Most important complication reported was renal involvement (10\% to $63 \%) .{ }^{21}$ In our study we observed $54 \%$ with renal involvement. Out of these $42 \%$ had RBC's in urine along with albuminuria and $12 \%$ had haematuria alone. Only $8 \%$ showed symptoms of renal involvement (dysuria) where as $46 \%$ of cases neither show any abnormality on routine urine examination nor any symptoms. We had one patient with intestinal perforation which was also reported in literature. ${ }^{17}$

Relapse reported in $1 / 3^{\text {rd }}$ of patients. ${ }^{5,11}$ In this study, except one patient all the others had exhibited recurrent nature of the disease. 


\section{Original Article}

Recurrence was noted in adults between the age group 20 and 40.

\section{Conclusion}

HSP is a small vessel vasculitis in response to any unknown foreign or endogenous antigen. The age of onset varied from below 7 to 58 years, with most of them below 20. The most important clinical presentation was palpable purpura in lower extremities. GIT and joint involvement were more prominent in our study conducted at

\section{References}

1. Tizard EJ. Henoch-Schönlein purpura. Arch Dis Child 1999; 80: 380-3.

2. Tizard EJ, Hamilton-Ayres MJJ. Henoch-Schönlein purpura. Arch Dis Child Educ Pract Ed 2008; 93: 1-8.

3. Iian Y, Naparstek Y. Schönlein Henoch Syndrome in adults and children. Semin Arthisis Rheum 1991; 21: 103-9.

4. Al-SheyyabM, Batiah A, El-Shanti H. Ann Trop Pediatr 1999; 19: 253-5.

5. Kaneki T, Kawashima A, Hayashida M, Yamaguchi S, Ogasawara H, Tsushima K et al.. A case of Henoch-Schönlein purpura after Staphylococcus aureus enterocolitis. Nippon Shokakibyo Gakkai Zasshi 2000; 97: 1278-82.

6. Costa MM, Lisbov M, Romeu JC, Caldeira J, De Queiroz V. Henoch-Schönlein Purpura associated with coxsackie-virus infection. Clin Rheumatol 1995; 14: 488-90.

7. Robinson BW. Henoch-Schönlein purpura due to food sensitivity. Br Med J 1977; 1: 510-11.

8. Szer IS. Henoch-Schönlein purpura. Curr Opin Rheumatol 1994; 6: 25-31.

9. Amorso A, Berrino M, Canale L, Coppo R, Cornaglia $\mathrm{M}$, Guarrera $\mathrm{S}$ et al.. Immunogenetics of Henoch-Schönlein disease. Eur J Immunogenet 1997; 24: 323-33.

10. Rai A, Nast C, Adler S. Henoch-Schönleinpurpura nephritis. J Am Soc Nephrol 1999; 10: 2637- 44.

11. Pavithran K. Henoch-Schönlein purpuraevolving into acute guttate psoriasis. Indicator J Dermotol Venerol Leprol 1990; 56: 147-8.

12. Mills JA, Micheal BA, Bloch DA, Calabrese LH, Hunder GG, Arend WP et al. The American the South Indian State of Kerala than mentioned in literatures. Recurrent nature of disease, seasonal variations and occurrence in same family members (not in blood relatives) at same time pointed to viral etiology. Though 54\% patients showed renal involvement on investigation, none had progressed to renal failure. Complications (renal involvement, and perforation) developed only in adults. Recurrences were noted in almost all patients $(98 \%)$. So, long term follow up is necessary.

College of Rehumatology 1990 criteria for the classification of Henoch-Schönleinpurpura. Arth Rheum 1990; 33: 1114-21.

13. Allen DM, Diamond LK, Howell DA. Anaphylactoid Purpura in Children (SchönleinHenoch Syndrome). AMA J Dis Child 1960; 99: 833-54.

14. Nielsen HE. Epidemology of Schönlein-Henoch Purpura. Acta Pediatr Scand 1988; 77: 125-31.

15. Golstein AR, White RH, Akuse R, Chantler C. Long term follow up of childhood Henoch-Schönlein nephritis. Lancet 1992; 339: 280-2.

16. Trapani S, Mariotti P, Resti M, Nappini L, De Martino M, Falcini F. Severe hemorrhagic bullous lesions in Henoch Schonlein purpura: three pediatric cases and review of the literature. Rheumatol Int 2010; 30: 1355-9.

17. Choong CK, Beasley SW. Intra-abdominal manifestations of Henoch-Schönlein purpura.J Pediatr Child Health 1998; 34: 405-9.

18. Mattoo TK, A 1-Mutair A, Al-Khatib Y, Ali A, Al-Shoaibani MO. Group A beta-hemolitic streptococcal infection and Henoch-Schönlein purpura with cardiac and neurological complication. Ann Trop Pediatr 1997; 17: 381-6.

19. Veraldi S, Mancuso R, Rizittelli G, Gianotti R, Ferrante P. Henoch-Schönlein syndrome associated with human Parvovirus B19 primary infection. Eur J Dermatol 1999; 9: 232-3.

20. Jensen B. Schönlein-Henoch's Purpura. Internal Medicine 1955; 152: 61-70.

21. Rieu P, Noel LH. Henoch-Schönlein nephritis in children and adults: Morphological features and clinicopathological correlations. Ann Med Interne 1999; 150: 151-9. 